\title{
SIMULATION-AIDED DETERMINATION OF AN EFFICIENCY FIELD AS A BASIS FOR MAXIMUM EFFICIENCY-CONTROLLER DESIGN
}

\author{
Lovrec, D. ; Tic, V.* \& Tasner, T.* \\ *University of Maribor, Faculty of Mechanical Engineering, Smetanova 17, Maribor, Slovenia \\ ${ }^{* *}$ HAWE Hidravlika d.o.o., Petrovce 225, Petrovce, Slovenia \\ E-Mail: darko.lovrec@um.si,vito.tic@um.si,t.tasner@hawe.si
}

\begin{abstract}
In the field of hydraulic drive technology various power supply systems are used within different power unit set-ups. The both of two mostly used drive concepts in modern electrohydraulic systems, a variable displacement pump driven by constant speed electric motor and fixed displacement pump driven by a variable speed electric motor, have some disadvantages, especially regarding the increasing demand for maximum efficiency of the entire power unit without lowering the high dynamics. The combination of a variable pump and speed-controlled electric motor, offers the option of setting two parameters of the drive, the rotational speed of the motor and the pump flow-rate.

Such a combination allows all power unit components to operate within the areas of their maximum efficiencies, the so-called maximum efficiency drive. A prerequisite for designing suitable controllers that would ensure the operations of individual components within the areas of maximum efficiency, regardless of the current operating point, is certainly knowledge about the efficiency area of the entire power unit. This paper presents a procedure for determining areas of efficiency, first on the basis of simulation and detailed models of each component, and later verification of the model using an experiment.

(Received in March 2015, accepted in May 2015. This paper was with the authors 1 month for 1 revision.)
\end{abstract}

Key Words: Hydraulic, Power Unit, Control Concepts, Efficiency Field, Simulation Results

\section{INTRODUCTION}

During ever-increasing demands regarding the efficiencies of hydraulic drive technology in terms of reducing energy consumption the drive, as well as the requirements and directives on the reduction of the noise and development tendencies in the direction of environment-and user-friendly drives, are leading to ever-increasing usages of electro-hydraulic drive technology. This is coming to light especially in those areas where higher energy density is required, for example, on modern machining centres and forming machines.

Hydraulics is mainly used in systems where big forces and power are required for normal operations. High power requirements are reflected in high energy consumption. Even the slightest (at percent level) optimisations of energy efficiency regarding such machines can result in significant savings over long operating periods. Therefore, improved efficiency and reduced energy consumption are two of the main goals during modern electrohydraulic drive systems design.

The efficiency increases can be achieved at the electrical and hydraulic energy conversion stage as well. The volumetric principle is mostly used in order to achieve a better adaption of the hydraulic supply system to the actual machines' needs. Two of the more commonly used drive concepts for volumetric adjustment of hydraulic energy are, by adjusting the displacement of a variable displacement pump at constant drive rotational speed, and by adjusting the rotational speed of a constant displacement pump.

Most machines within the field of hydraulic drive technology are still using the classic drive concept: a variable displacement pump driven at constant speed. The desires for greater 
robustness and lowering the price of hydraulic drives over recent years, as well as low prices of variable-frequency drive controllers, have led to more and more popularity for using speed controlled constant pumps. However, such a concept cannot meet the dynamic requirements of the classic drive concept [1].

The more effective approach to adapting to the needs of the energy supply, which enables at the same time a high dynamic, represents the combination of a variable pump and a speedadjustable electric motor. Within this drive concept two values need to be adjusted: the rotational speed of the electric drive motor and the displacement volume of the used variable pump as well - sc. the bi-variable drive (control) concept. All three mentioned adaptive supply principles with main properties are given in Table I.

Using a variable pump and constant motor $(\mathrm{C} 1)$ is the concept with a fairly high dynamic but a lower overall efficiency, (when also considering the electric motor efficiency at the pump's operating point), and less robust than a constant pump and variable speed drive (C2).

$\mathrm{C} 2$ was asserted mainly due to good efficiency and a wide operating range [2]. It also excels at lower operating costs and a consecutively smaller effect on the environment. Lower operating costs and higher efficiency come mainly from the more efficient connection of the motor to the electrical grid via a variable-frequency drive controller [3]. However, C2 also has one major drawback: a slow system response that occurs due to the moments of inertia of the rotating parts (motor rotor and rotary parts of the pump). The response of $\mathrm{C} 1$ is up to 5 times faster than the response of $\mathrm{C} 2$ [1] but both responses are good enough for most hydraulic applications [4].

Table I: Three different electrohydraulic supply concepts in comparison [3].

\begin{tabular}{|c|c|c|c|}
\hline & $\begin{array}{l}\text { Concept } 1 \text { (C1): } \\
\text { asynchronous motor, } \\
\text { variable axial piston } \\
\text { pump }\end{array}$ & $\begin{array}{c}\text { Concept } 2 \text { (C2): } \\
\text { variable frequency drive } \\
\text { controller, } \\
\text { asynchronous motor, } \\
\text { constant gear pump }\end{array}$ & $\begin{array}{c}\text { Concept } 3(\mathbf{C 3}) \text { : } \\
\text { variable frequency drive } \\
\text { controller, } \\
\text { asynchronous motor, } \\
\text { variable axial piston } \\
\text { pump } \\
\end{array}$ \\
\hline $\begin{array}{l}\text { Pump's rotational } \\
\text { speed }\end{array}$ & constant & variable & variable \\
\hline Pump's displacement & variable & constant & variable \\
\hline Scheme & $p, Q$ & $p, Q$ & $p, Q$ \\
\hline Efficiency & lower & higher & highest \\
\hline Reliability & high & high & high \\
\hline Robustness & less & more & less \\
\hline Operating costs & highest & higher & lower \\
\hline System dynamics & $\begin{array}{l}\text { highest } \\
4.4 \\
\end{array}$ & $\begin{array}{c}\text { low } \\
1\end{array}$ & $\begin{array}{c}\text { control principle } \\
\text { dependent (approx. 4) }\end{array}$ \\
\hline Purchase price & higher & lower & highest \\
\hline
\end{tabular}

If we look for the highest efficiency of the entire drive train at high responsiveness, the third concept (C3) is promising drive concept. The biggest drawback of C3 is the highest purchase price amongst all the concepts because a variable frequency drive controller and a variable displacement pump are needed, where the variable displacement pump is the more expensive component of the required components [5]. Additionally is also necessary to pay 
attention to the hydraulic fluid cleanliness level and, of course, to know the values of the efficiencies of each component within the entire field regarding all operating parameters.

\section{DRIVE TRAIN}

When designing the appropriate control strategies and defining the controller parameters, it needs to be considered that the speed of the electric drive as well as the rate of flow setting of the pump are always located in the area with an optimal i.e. highest efficiency, in respect to the drive current operation point (pressure and flow). Due to these features and requirements this modern drive concept is called the eta-drive concept.

The first step towards this direction the whole field of efficiency need to be known. This can be done using simulation based on detailed models of all drive components or be established by large-scale measurements for all operating parameters. The so-obtained data is then used in the form of a look-up table on the basis of defining the amount of electric motor speed and the displacement of the variable pump.

In order to ensure the required hydraulic power $P_{h}$ at the desired operating point at the lowest energy consumption at the source $P$, it is necessary to take into account all the components of the power drive system: an electric motor with controller, hydraulic pump, hydraulic tubing, and the hydraulic load itself - Fig. 1.

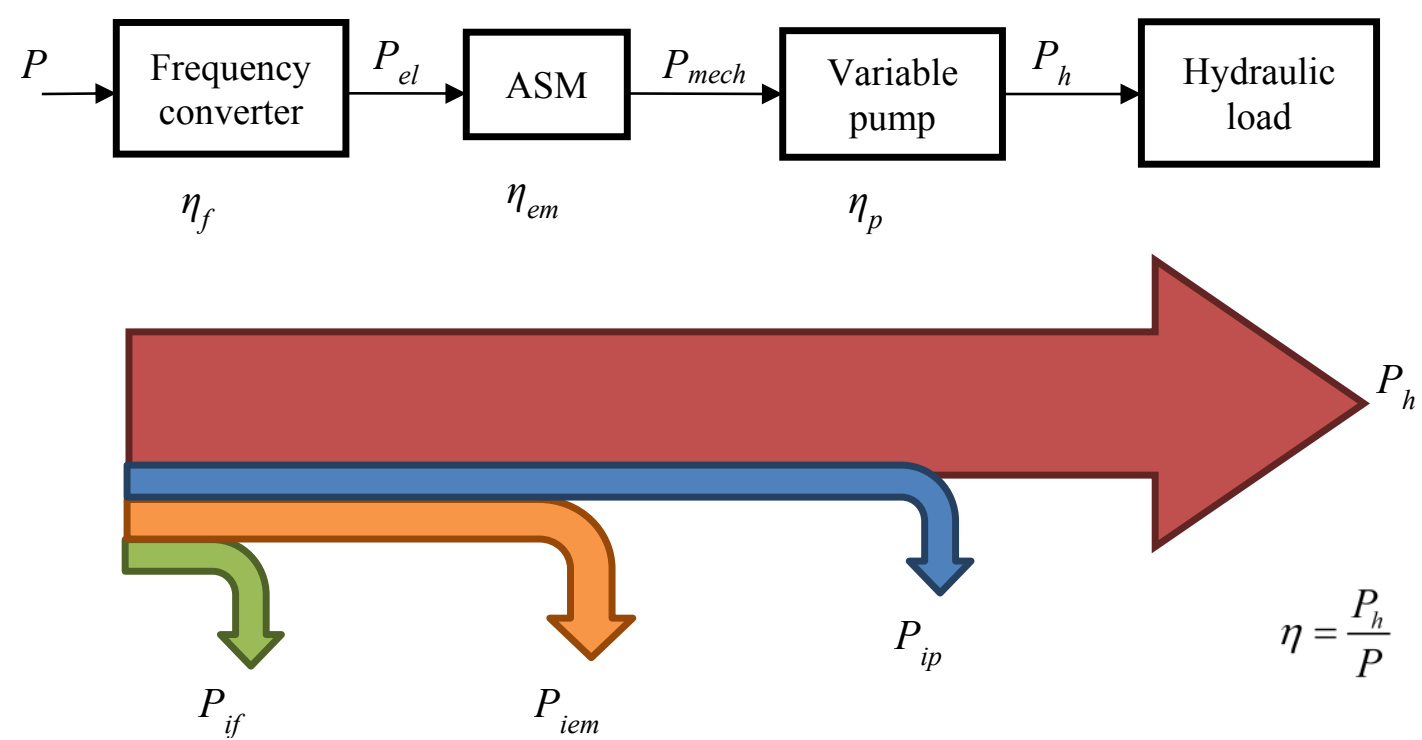

Figure 1: Graphic display of power flow within an electro-hydraulic system.

When converting electrical energy into hydraulic losses occur in all of these subsystems. Also the frequency converter which provides power to the electric motor is not ideal meaning that some power $P_{i f}$ is lost and its efficiency $\eta_{f}$ is less than 1. A similar situation occurs in the conversion of electrical energy into mechanical where, due to the efficiency of the electric motor $\eta_{m}$, power losses $P_{i m}$ are present in motor. The same story is repeated for the hydraulic pump $\left(\eta_{p}, P_{p}\right)$. This can mathematically be written in the form of Eq. (1).

$$
P_{h}=P_{\text {mech }} \cdot \eta_{p}=P_{e l} \cdot \eta_{e m} \cdot \eta_{p}=P \cdot \eta_{f} \cdot \eta_{e m} \cdot \eta_{p}=P \cdot \eta
$$

The system was built for the purpose of determining the efficiency fields at every operating point of the drive system: frequency controlled asynchronous motor in combination with an adjustable axial piston pump, hydraulic lines, hydraulic loads including the control and monitoring parts of the drive. Fig. 2 presents a block diagram of the test rig and corresponding flow of power and signals, while Fig. 3 presents a detailed hydraulic scheme. 


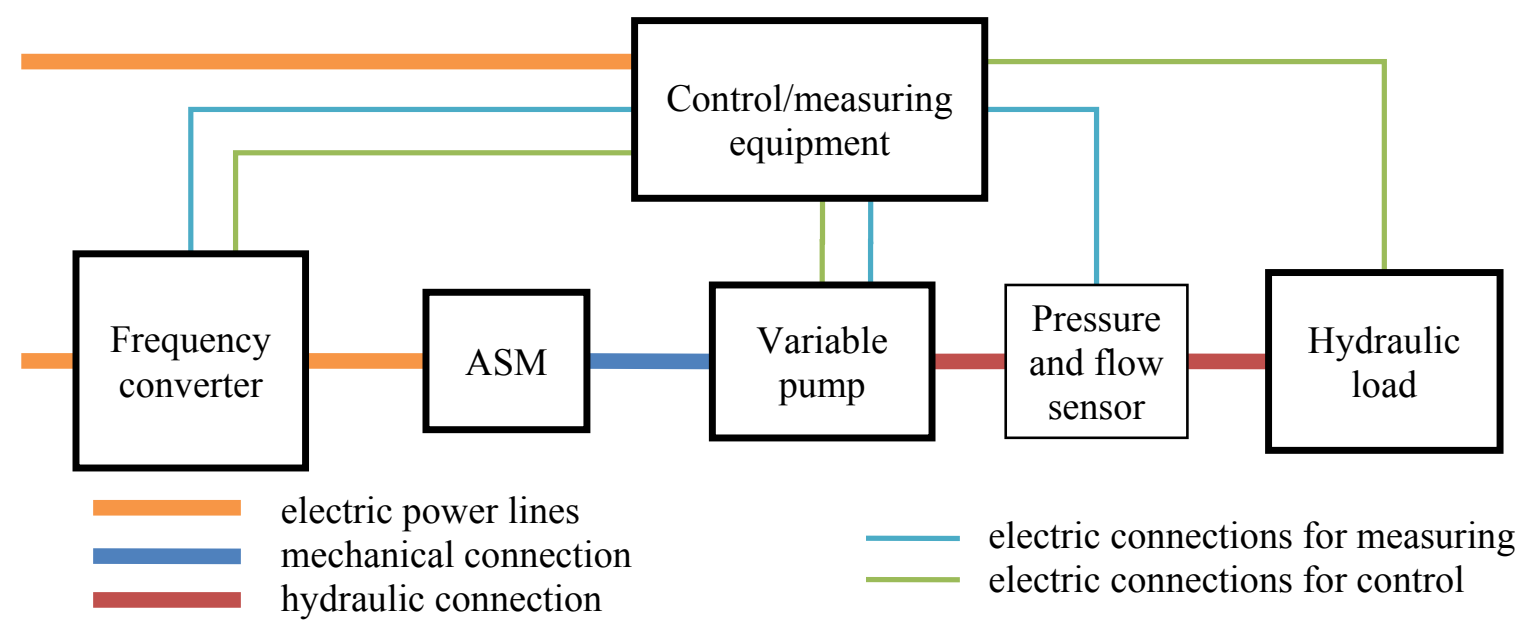

Figure 2: Block diagram of the test rig.

A standard adjustable axial piston pump with an adjustable swash plate and corresponding control electronics was used as the hydraulic pump, which was powered by three-phase asynchronous electric motor in combination with a frequency converter that allows controlling of the motor at various loads and rotating frequencies.

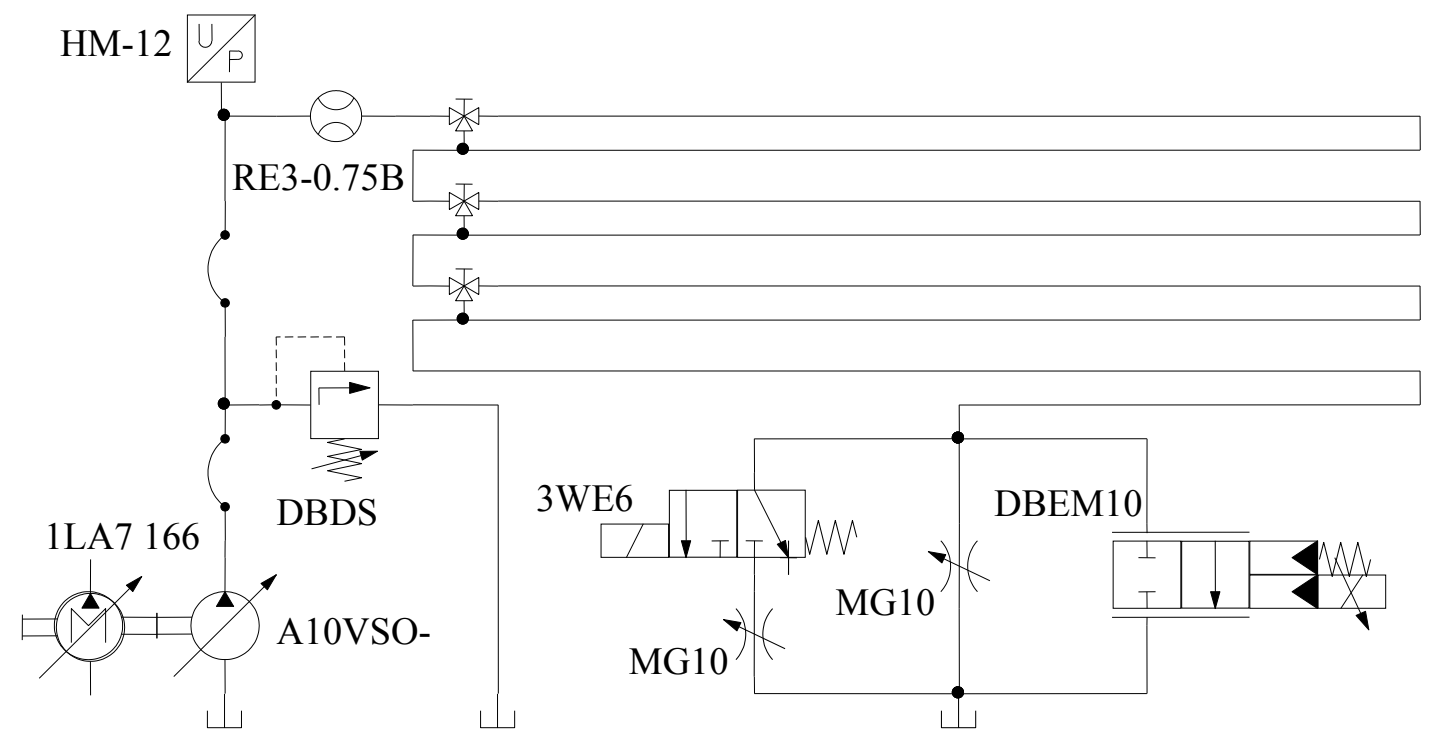

Figure 3: Detailed hydraulic scheme of the test rig.

Monitoring, data acquisition and control of the test rig is performed on an advanced CompactRIO controller (NI cRIO-9022). This controller integrates the processor that operated in real time, the FPGA circuit, and the input/output modules. FPGA is connected to the realtime part via the FIFO (First In, First Out) buffer. The real-time part is responsible for storing data on the built-in flash memory and for controller parameterisation and reference signals generation in cases of further implementations of the actual eta-control concept.

\section{EFFICIENCY FIELD OBTAINED USING MODELLING AND SIMULATION APPROACHES}

The starting point is a good knowledge of the individual electrical and hydraulic components, their specific structures and modes of operation. It will be necessary to evaluate all existing drive components and compare them during simulation as well as experimentally. 
The simulation model of the considered energy-efficient drive concept (C3) consists of a variable-frequency drive controller, asynchronous motor connected to it, variable displacement axial piston pump, and hydraulic tubing with load. The following subsection present models of all the components used during simulation.

\subsection{Asynchronous motor model}

The simplest model of a three-phase asynchronous motor consists of two pairs of magnetically coupled symmetric three-phase windings. Both of the three-phase windings (stator and rotor winding) are identical. The same model also applies for a squirrel-cage rotor, where currents start flowing due to electro-magnetic induction. The more commonly used model for dynamic simulations of asynchronous motors is based on the so-called ' $\mathrm{T}$ ' equivalent circuit. Such a model is used for static and dynamic simulations, although it neglects core losses (saturation and eddy current losses) [6].

The following equations can be obtained from the ' $T$ ' equivalent circuit for a squirrel-cage rotor:

$$
\begin{aligned}
\vec{U}_{s} & =R_{s} \vec{I}_{s}+L_{s} \vec{I}_{s}+L_{M} \vec{I}_{r} \\
\overrightarrow{0}=\vec{U}_{r} & =R_{r} \underline{I}_{r}+L_{r} \underline{I}_{r}+L_{M} \vec{I}_{s}
\end{aligned}
$$

where $\underline{\vec{U}} / \underline{\vec{I}}$ are vectors of the voltage/current phasors for each phase, $R$ winding resistances and $L$ inductances, where subscript $r$ denotes rotor, $s$ stator and $M$ mutual input power; electrical, mechanical and hydraulic powers. The electromechanical torque can be written as:

$$
\dot{\vec{I}}_{s}^{T} L_{M} \cdot \dot{\vec{I}}_{r}=T_{e m}=J \frac{\mathrm{d} \Omega}{\mathrm{d} t}+b \cdot \Omega+T_{L}
$$

where $\Omega$ is the mechanical rotational frequency of the rotor, $b$ the viscous friction coefficient and $T_{L}$ the load torque. [7].

All the necessary parameters of the asynchronous motor needed for the simulation model were calculated from the measurement results of the locked rotor and no-load tests.

\subsection{Variable-frequency drive controller model}

The variable-frequency drive controller is a device which can change the rotational frequency or torque of an electric motor by modifying the frequency and amplitude of a motor's supply voltage. A typical variable-frequency drive controller consists of:

- a rectifier, rectifies input AC voltage,

- DC link, energy storage,

- an inverter, converts DC to AC,

- and a control circuit which measures motor currents and controls the inverter.

\section{Rectifier model}

The more commonly used rectifier type in variable-frequency drive controllers is a fullwave rectifier with LC filter. Such a rectifier consists of three pairs of rectifier diodes and a filter inductor, which charge the DC link capacitor.

Assuming that the LC filter is ideal and that the voltage drops on the diodes are constant, the rectifier losses can be expressed as Eq. (4), where $U_{F}$ is the diode's forward voltage. The factor 2 in the equation represents current flow through one lower and one upper diode [8].

$$
P_{R E C T}=2 \cdot I_{D C} \cdot U_{F}=2 \cdot\left(U_{D 0}+R_{D} \cdot I_{D C}\right) \cdot I_{D C}
$$

An ideal DC link capacitor was used in our variable-frequency drive controller. 


\section{Inverter model}

Most of the inverters are controlled based on the principle of space vector modulation. The three- phase vector Pulse Width Modulation (PWM) inverter requires three transistor bridges. Each bridge consists of two transistors operating within the switching region. Such an inverter can drive any three-phase load, with or without the neutral line [9].

The transistors used in the inverters are either Isolated Gate Bipolar Transistors (IGBTs) or Metal Oxide Semiconductior Field Effect Transistor (MOSFETs) and are controlled by a microcontroller. As our inverter uses MOSFETs a simplified loss model will be used for switching and conductive losses of MOSFETs. Energy lost in one switch of both transistors in a transistor bridge can be expressed as Eq. (5) where all the data are characteristics of the MOSFET except that $U$ and I depend on the inverter load and represent the voltage on the MOSFET and the current flowing through the MOSFET, respectively [10].

$$
W_{S W}=\frac{P_{S W}}{f_{S W}}=\frac{1}{2} I_{D} U_{D}\left(t_{O N}+t_{O F F}\right)+\frac{1}{2}\left(C_{G D}+C_{D S}\right) U_{D}^{2}
$$

The conducting losses for the transistors during their on-times are in Eq. (6):

$$
P_{O N}=R_{D S(o n)} \cdot i_{a}^{2}+R_{D S(o n)} \cdot i_{b}^{2}+R_{D S(o n)} \cdot i_{c}^{2}=R_{D S(o n)} \cdot\left(i_{a}^{2}+i_{b}^{2}+i_{c}^{2}\right)
$$

and total losses in Eq. (7):

$$
P_{I N V}=P_{O N}+\frac{W_{S W}}{f_{S W}}
$$

where $f_{S W}$ represents the inverter switching frequency.

\section{Control circuit model}

Most variable-frequency drive controllers control the drives on the principle of Sensorless Vector Control (SVC). SVC needs an inverse dynamic model of the asynchronous motor in $\mathrm{dq}$ coordinates for it to function. Synthesis of such a model is beyond the scope of this article.

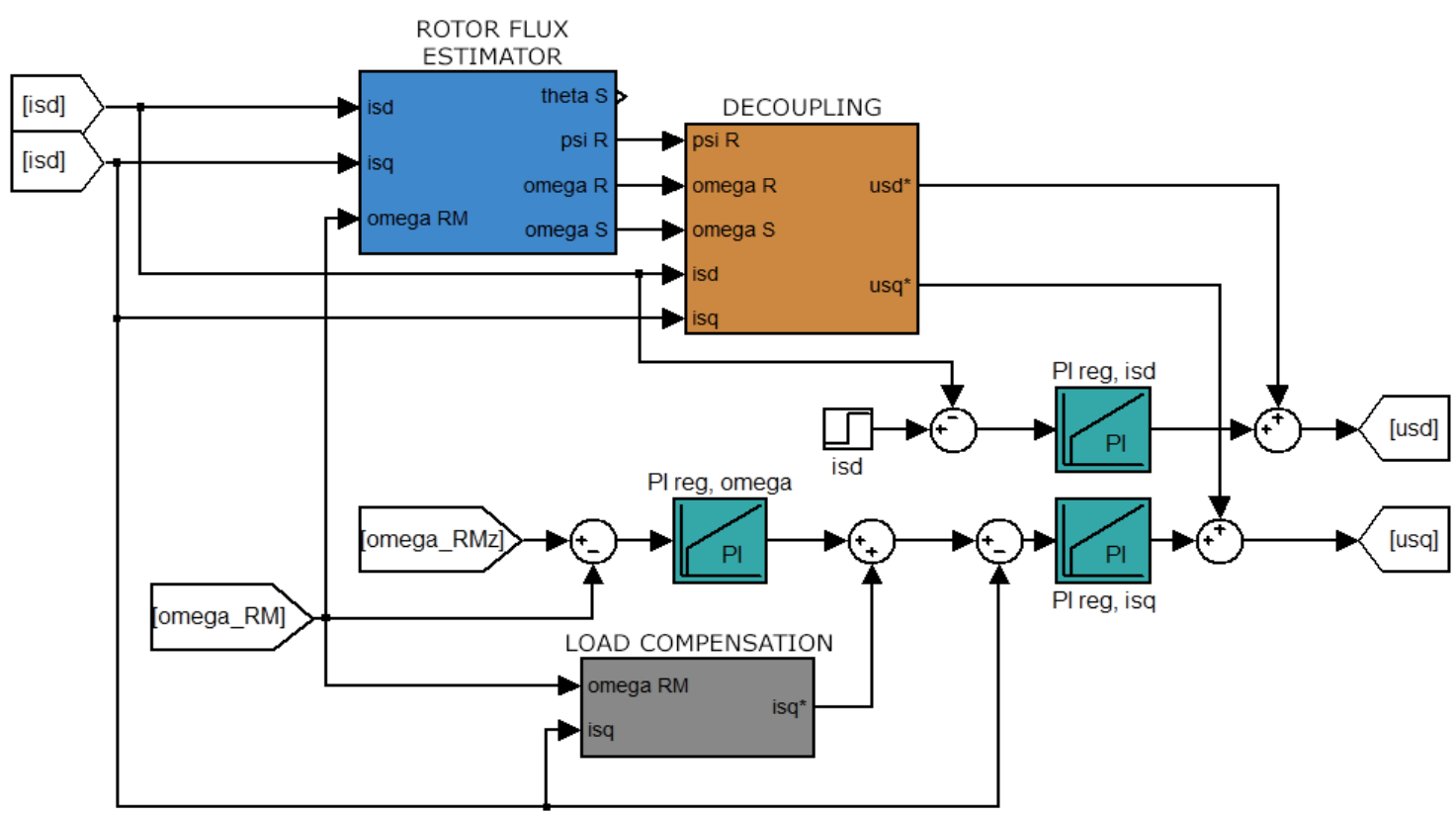

Figure 4: Control circuit block diagram.

The basic parts of its synthesis are presented in [11]. A simplified block diagram of the control circuit is shown in Fig. 4, with its main blocks: 
- rotor flux estimator, rotor flux is needed for decoupling,

- decoupling, decouples $\mathrm{d}$ and $\mathrm{q}$ voltage components so each can be changed without affecting the other,

- two current controllers, control magnetising (d) and torque (q) current components by changing their voltages,

- speed controller, controls motor rotational speed by changing the torque current component,

- and load compensation, detects the load and increases the required torque current accordingly in order to maintain the desired rotational speed.

\subsection{Variable displacement axial pump model}

A variable axial piston pump in a swash plate design form was used for the conversion of mechanical energy into hydraulic. The flow can be set by adjusting the swash-plate angle.

Wilson [12] started modelling hydraulic pumps at the end of the first half of the $20^{\text {th }}$ century. He designed a static model, which takes into account the volumetric and friction losses of pumps. His model was later improved by certain authors and their work was summed-up by Rydberg [13]. However, those models are useful only for the already-made and tested pumps because the coefficients are obtained from measurements and experiments on the test rigs [14]. The used models are based on Wilson's model and use some modifications mentioned by Rydberg.

The flow $Q$ of the hydraulic fluid through the pump is proportional to the rotational speed $n$ of the pump and the value of the swash plate angle up to the maximal pump displacement $V_{g}$ which is a characteristic property of each pump. At higher pressures the pump's flow-rate starts to decrease slowly due to the compressibility of the fluid and the increased leakage losses [15]. These losses are covered under the concept of the volumetric efficiencies of the pumps, which depends on the pressure difference $\Delta p$ that the pump must overcome. Such losses can be easily presented (in an analogous manner to electrical engineering) as a parallel hydraulic resistance $R p$ of the ideal pump:

$$
Q=n \cdot \alpha \cdot V_{g}-\frac{\Delta p}{R_{p}}
$$

The pump's operating torque is proportional to the pressure difference that the pump creates, due to the law of energy conservation. The torque $T$ must, in addition to creating pressure difference, overcome the losses that occur due to lubrication of the pump and friction between the moving (rotating) parts of the pump $b$. Additional losses during the friction between piston and walls $C$ must be taken into account.

$$
T=\frac{50}{\pi} \cdot \Delta p \cdot \alpha \cdot V_{g}+\omega \cdot \alpha \cdot b+\omega \cdot \frac{\tan \alpha}{\tan \alpha_{\max }} \cdot \mathrm{C}(\Delta p)
$$

\subsection{Hydraulic tubing model}

The dynamic behaviour of the fluid in the pipeline can be modelled in several different ways. The more exact model is based on the Navier-Stokes equations and the law of mass conservation which results in a system of partial differential equations which are (due to its complexity and the details) too time-consuming for such simulations.

Such an exact model of hydraulic pipeline is not needed. Therefore a more appropriate was chosen - a discrete model also known as the model with concentrated parameters [16]. This discrete model is analogous to electrical circuits used by electrical engineers, where the properties of a circuit are represented by resistance, capacitance, and inductance. In hydraulics the properties of a pipeline system are hydraulic resistance $R_{H}$ (pressure difference $=$ pressure 
drop in a tube due to flow resistances), hydraulic capacitance $C_{H}$ (pressure difference in a tube due to tube volume increase/decrease) and hydraulic inductance $L_{H}$ (pressure difference due to fluid acceleration/deceleration).

\section{DETERMINATION OF EFFICIENCY FIELD FOR THE ENTIRE} POWER UNIT

As presented in Fig. 1, which schematically shows the power flow within the electrohydraulic system, the efficiencies of individual subsystems vary depending on their operating points - operating conditions:

- The efficiency of the frequency converter is mainly depends on the pulse-width modulation switching frequency and current values of motor current and voltage.

- The efficiency of the asynchronous motor depends on its rotational frequency and the torque produced.

- The efficiency of the hydraulic pump depends on the fluid flow, pressure and resistance in the hydraulic system. In the application of variable displacement pumps the efficiency is also depends on the pump's setting.

As the operating points of the various systems are very closely related to each other, it is urgent to treat the electrohydraulic system as a whole. This can be achieved by integrating simulation models as presented in the previous section and on the basis of which we can simulate all three types of power train - Table I. In our case it is to deal with the most complex case - power unit as a speed regulated asynchronous electric motor in combination with an adjustable axial piston pump and hydraulic load.

As for the purpose of determining the efficiency field as a function of pressure and flowrate it is more appropriate to use a proportional valve for hydraulic load. In this way we determine what kind of flow the pump may provide at a particular operating point (flow, pressure), as well as obtaining the value of the efficiency at the working point. The efficiency depends on the operating point, as shown in Eq. (10), which is obtained from combining Eqs. (1) and (9).

$$
\eta(p, Q)=\frac{P_{h}}{P}=\frac{0,6 \cdot p \cdot Q(n, \alpha)}{P}=\frac{0,6 \cdot p \cdot n \cdot \alpha \cdot V_{g}}{P}
$$

Firstly the efficiency field was obtained on the basis of simulations, and later on the obtained results were confirmed by experiment. Within the simulation we had an additional opportunity to monitor a wide variety of parameters on a simulation model, which in reality is impossible or it is very difficult to measure, for example, the torque component of the rotor current, rotor magnetic centre, ... in regard to the experimental measurements, we had to select those that could be measured (with the available equipment).

\subsection{Determination of efficiency field based on simulation}

Simulation model of the presented system has been developed in MATLAB Simulink software. A fixed time-step of $1 \mu \mathrm{s}$ was used and the ODE4 solver (Runge-Kutta) was used for solving the equations. Such a small time-step was chosen due the pulse-width modulation of the frequency converter. The entire model was comprised of 600 blocks, of which 18 were integrators and one fourth of the order transfer function, which meant that the power unit was represented by a differential equation of the $22^{\text {nd }}$ order. Due to the complexity of the model and the short time-step simulation that took place on a modern PC $\left(3^{\text {rd }}\right.$ generation Intel i7 processor with 12GB RAM) at a ratio of 720:1 - to simulate one second operations of the power unit needed 12 mins. Such a model can be used for determining the efficiency of the electrohydraulic system, as well as for defining its dynamics. In parallel with the simulation 
we could practically test all three power units (shown in Table I) and their control concepts and by measuring determine the efficiencies and dynamics of such systems on a test rig.

The pump flow can be influenced by the pump displacement setting and/or by changing the speed of the pump (10). The same flow can be achieved by different combinations of rotational speed and pump displacement settings. The working point is so determined by setting of three variables marked red in Fig. 5, whereas the measured ones in blue.

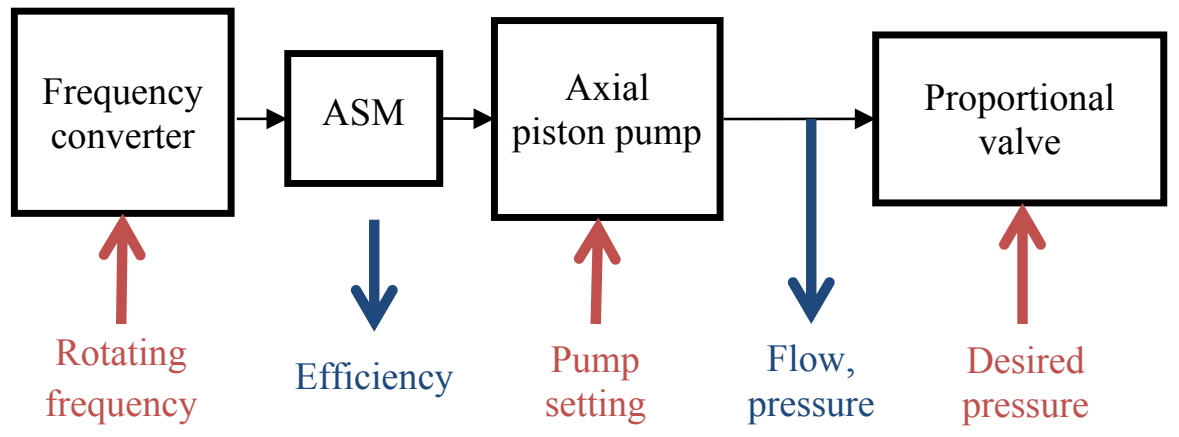

Figure 5: Block diagram of test rig set-up for measuring efficiency of power unit.

As the operating point in this case depends on three variables (rotational speed, pump setting and desired pressure), the efficiency of this set-up also depends on them.

The efficiency of the power train may therefore be represented on a four-dimensional graph as efficiency depending on the rotational speed, pump setting and pressure. Since the fourth-dimensional surface graphs are difficult to draw and very difficult to read, we can simplify the graph and present the results on a scattered three-dimensional graph on which the fourth dimension is represented by a colour. The same colour lines represent the same pump setting. In order to improve the transparency of the graph the points at the same pressure are interconnected using lines. The results obtained by simulation are shown in Fig. 6.

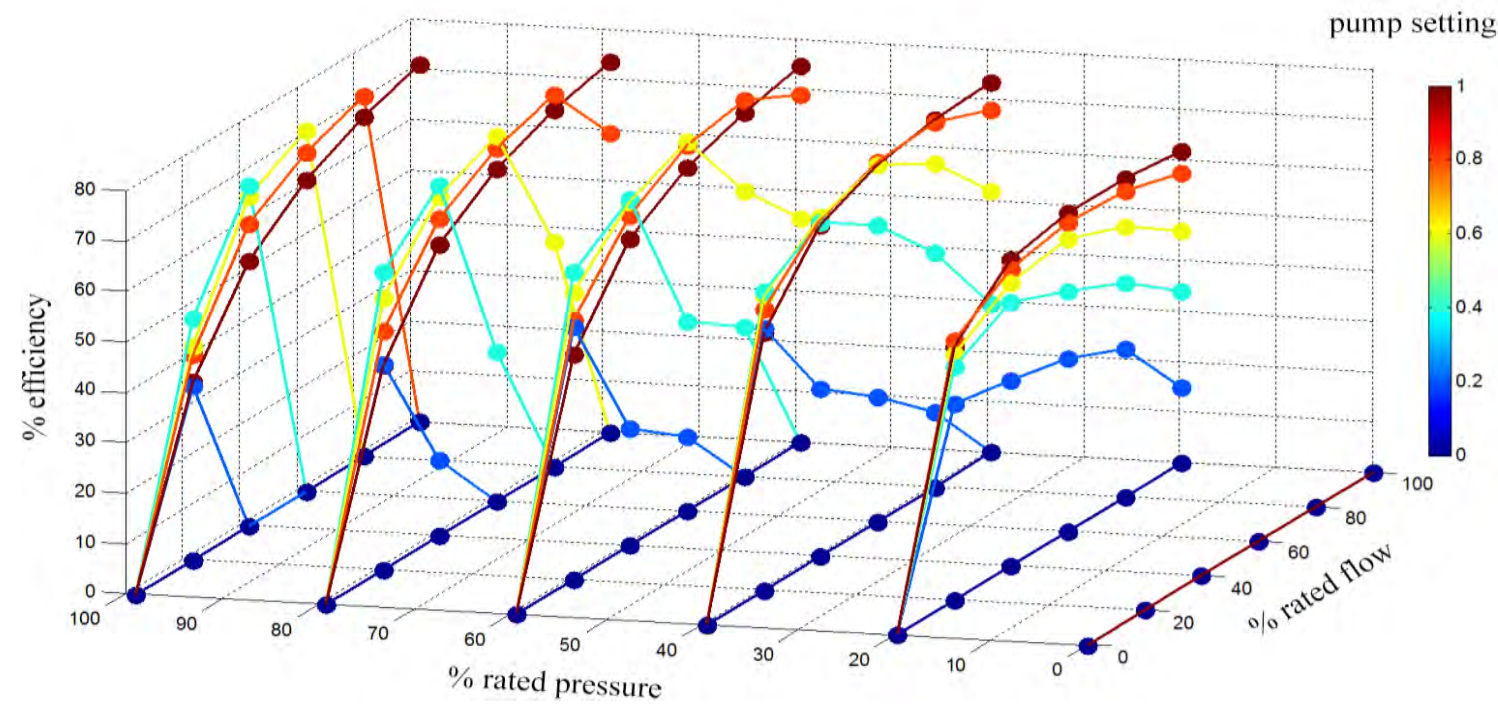

Figure 6: The efficiency of $\mathrm{C} 3$ power train as a function of pressure, flow and pump setting simulation results.

\subsection{Determination of efficiency field based on experimentation}

A practical efficiency field was obtained by measurements performed on a test rig as presented in Fig. 2 with all the components that were used for the design of a mathematical model of the drive. The corresponding equivalent block diagram of the test rig is shown in Fig. 7 with additionally added measured and controlled variables. 


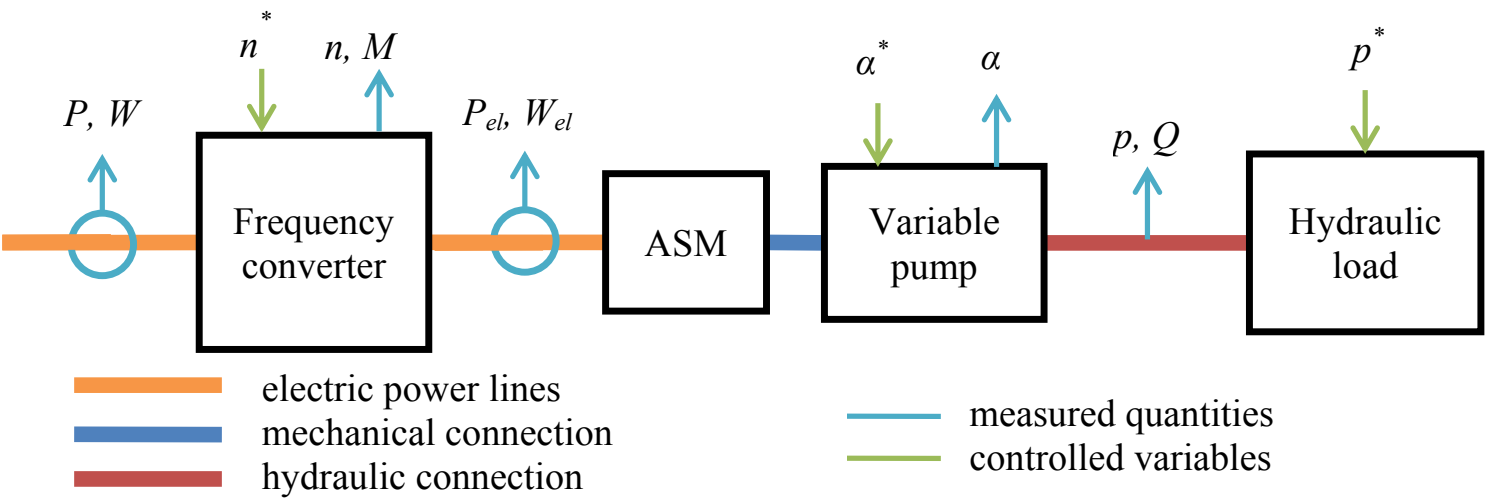

Figure 7: Block diagram of the test rig with measured and controlled variables.

During the measurement of power train efficiency, depending on the operating point, the following variables were measured:

- power input before the frequency converter (manually with a clamp metre),

- electric power between asynchronous motor and frequency converter (manually with a clamp metre),

- mechanical power as a product of rotational frequency and torque:

- rotational frequency through via the analogue output of the frequency converter (automatic) and

- torque via the analogue output of the frequency converter (automatic), the frequency converter calculates the torque from the electric current,

- hydraulic power as a product of flow and pressure

- pump flow by measuring the turbine (manually) and

- pump pressure by a pressure sensor (automatic),

- pump setting via the analogue output of the control card of the axial piston pump (automatic).

All automatically measured quantities were recorded by the controller, while other quantities were added manually. Then the efficiency of the entire system or only the partial efficiencies could be calculated according to Eq. (1). The results of measuring efficiency field are shown in Fig. 8.

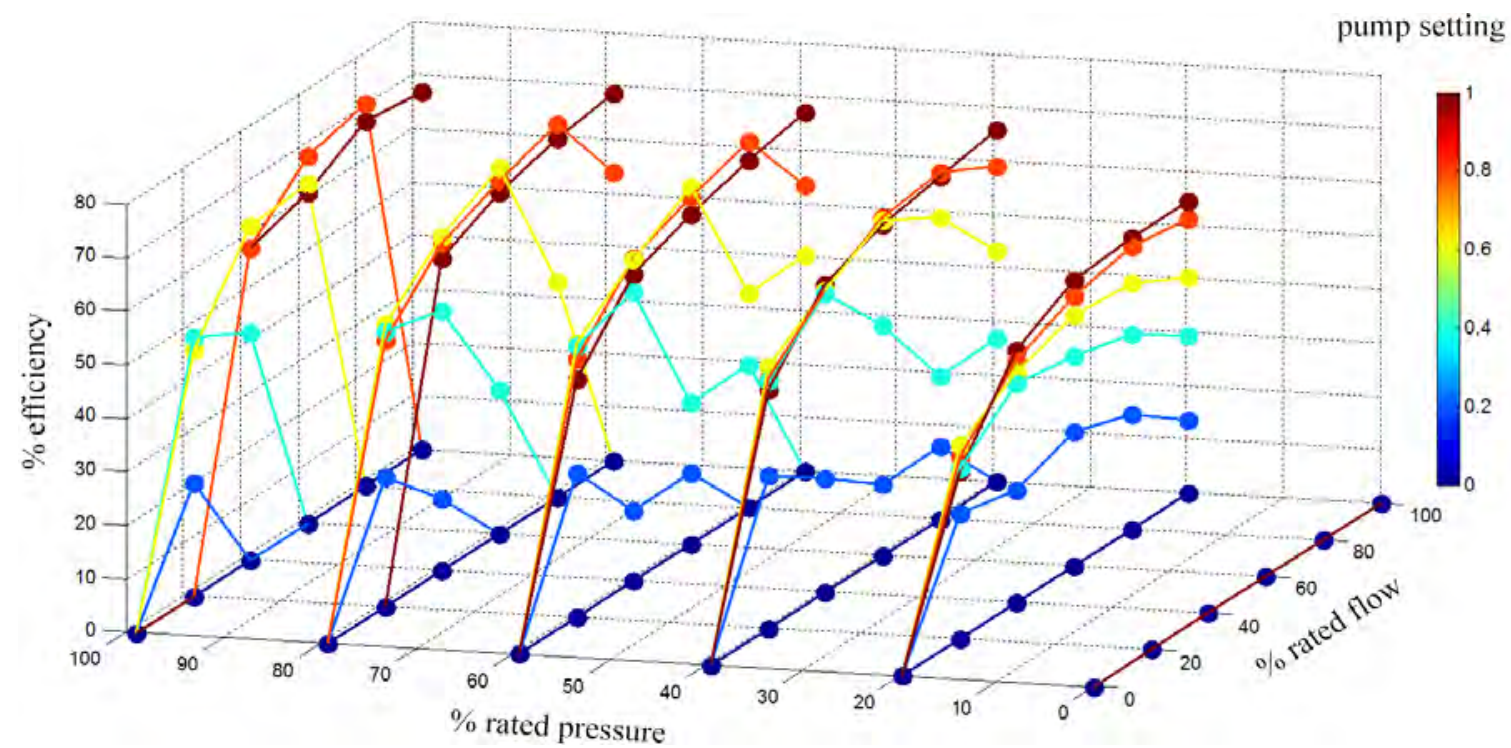

Figure 8: The efficiency of the $\mathrm{C} 3$ power train as a function of pressure, flow and pump settings experimental results. 


\subsection{Comparison between the results - the verification of model accuracy}

Even at first glance, the efficiency fields shown in Figs. 6 and 8 obtained by the simulation and experiment are very similar. Differences only arise at low powers.

In order to facilitate the comparability it made sense to make another graph to show the greatest possible efficiency of the powertrain as a function of the operating point. The results obtained by the experiment are presented in Fig. 9, whilst Fig. 10 presents the results obtained by the simulation and Fig. 11 the difference between the experiment and the simulation.

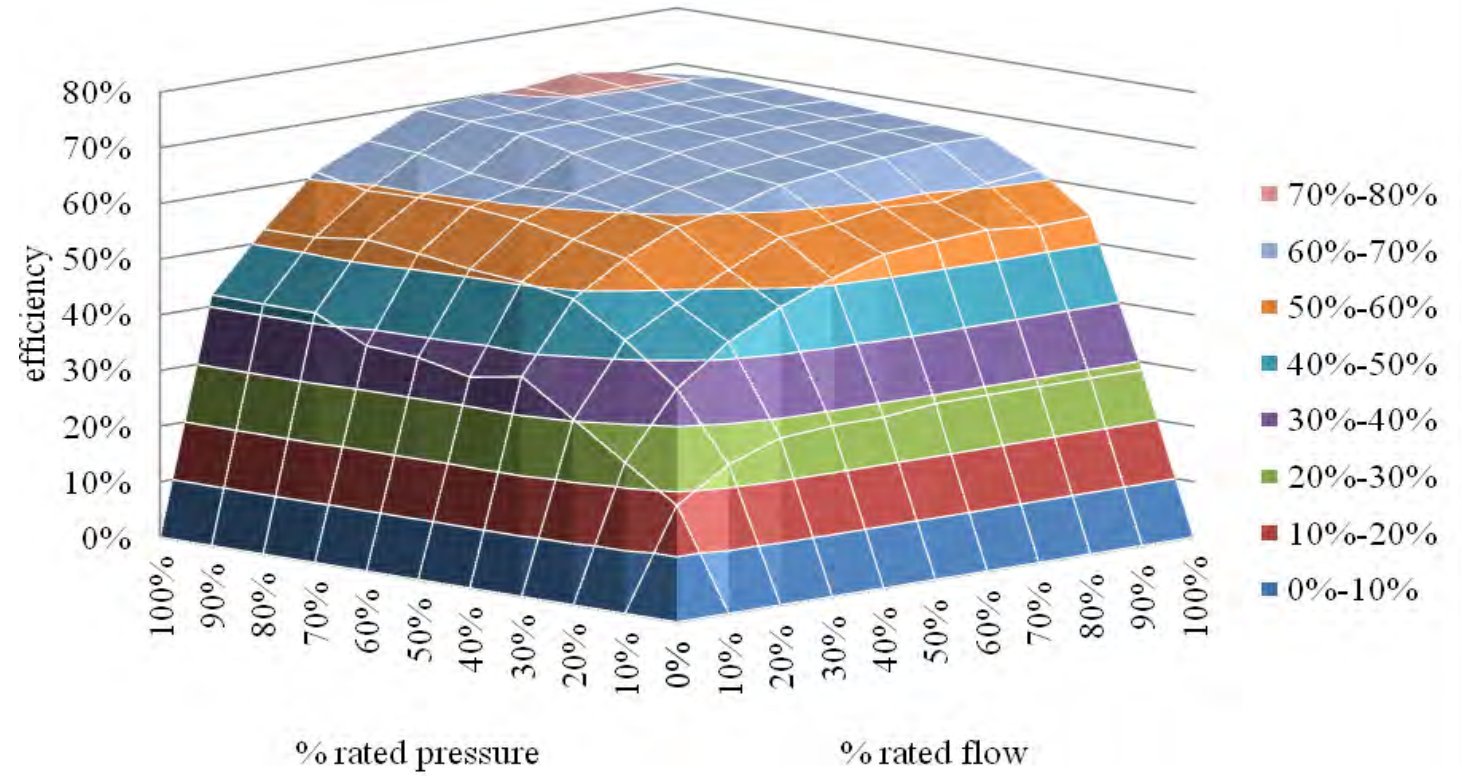

Figure 9: The maximum efficiency of the $\mathrm{C} 3$ power train as a function of pressure and flow experimental results.

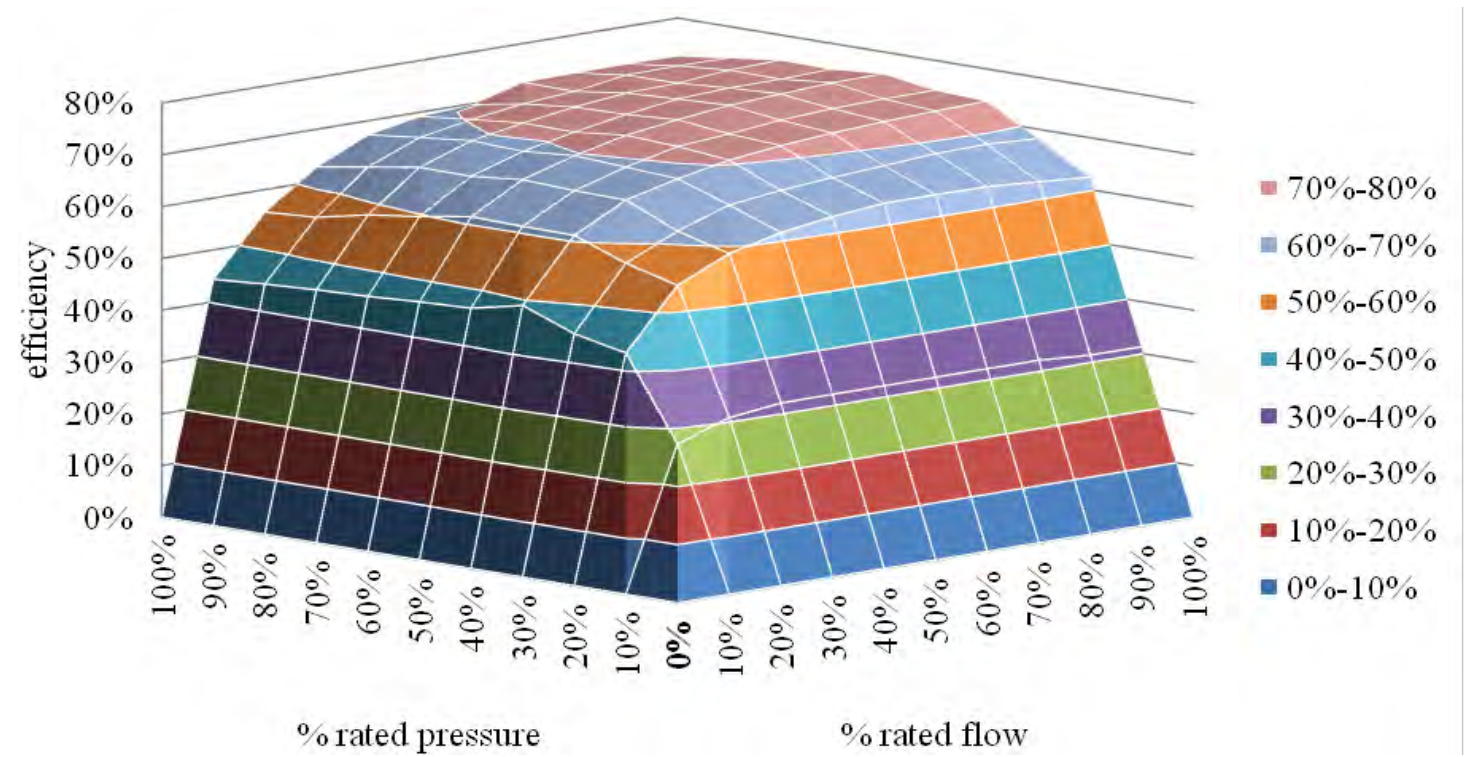

Figure 10: The maximum efficiency of the $\mathrm{C} 3$ power train as a function of pressure and flow simulation results.

All the important information for C3 power train are summarised in Table II, which presents the maximum efficiency of the power train and the operating point at which the maximum efficiency was reached. 


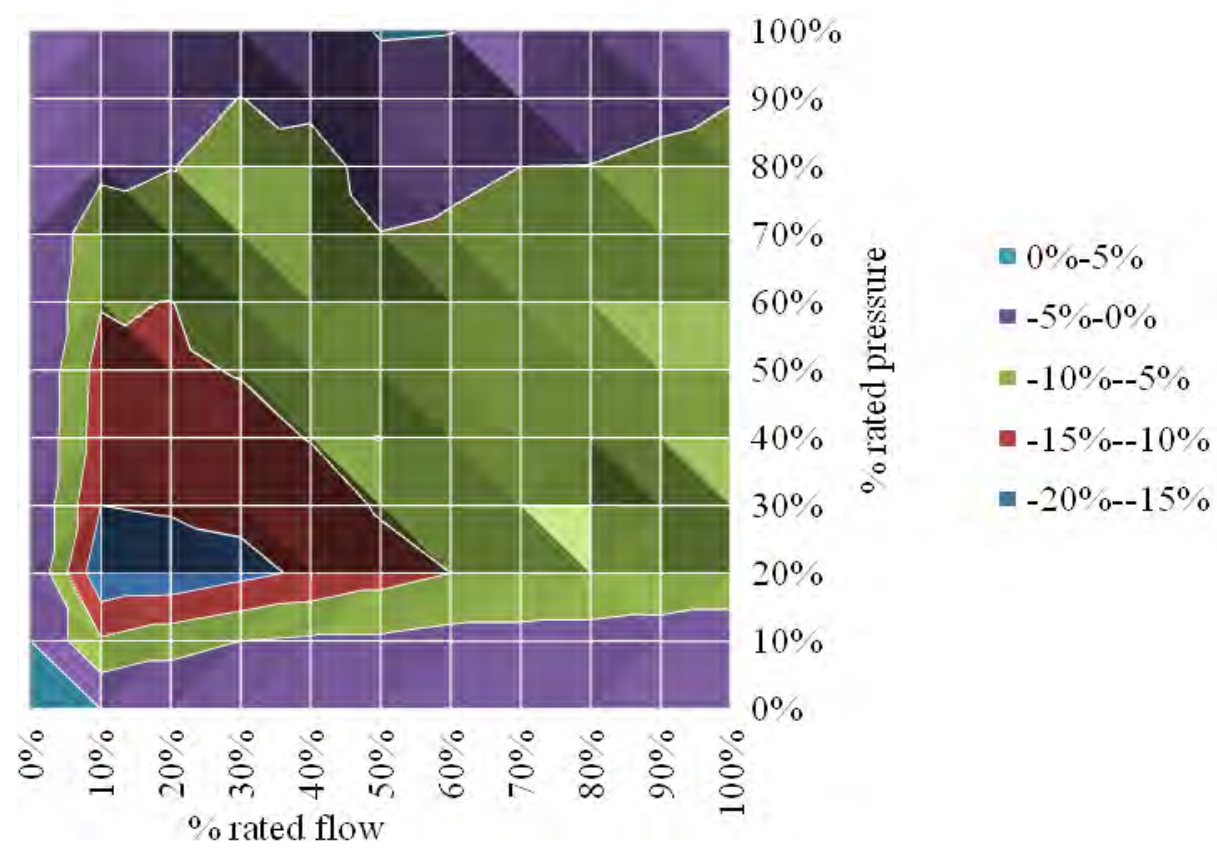

Figure 11: The maximum efficiency of the NN powertrain as a function of pressure and flow difference between experimental results and the simulation.

Table II: Comparison of powertrains' efficiencies.

\begin{tabular}{|c|c|c|c|c|}
\hline $\begin{array}{c}\text { Maximum efficiency } \\
\text { (operating point) }\end{array}$ & $\begin{array}{r}\text { Average efficiency } \\
\text { plain }\end{array}$ & $\begin{array}{c}\text { Efficiency pressure } \\
\text { holding }(100 \%, 20 \%)\end{array}$ & $\begin{array}{c}\text { Efficiency idling } \\
(20 \%, 100 \%)\end{array}$ \\
\hline $\begin{array}{c}71 \% \\
(100 \%, 80 \%)\end{array}$ & $57.7 \%$ & $57.8 \%$ & $52 \%$ & $55 \%$ \\
\hline
\end{tabular}

Also the average efficiency for all operating points was calculated. The average efficiency was initially calculated as the plain average of all the efficiencies and then weighted by the power at a given point (the point that has more power also has a higher weight). Furthermore, the efficiencies are presented in the cases of pressure holding where the pressure was high $\left(p=100 \% p_{n}\right)$ and the flow low $\left(Q=20 \% Q_{n}\right)$, and idling where the pressure was low $\left(p=20 \% p_{n}\right)$ and the flow high $\left(Q=20 \% Q_{n}\right)$.

In addition to the efficiencies at various operating points further studies allowed us to evaluate the dynamics and the efficiencies of the system during different working cycles (either by simulation or experiment), which enabled us even more detailed comparisons between the different power trains and control concepts.

For the purposes of effective implementation of the maximum efficiency, the controller's evaluated efficiency fields obtained by simulation or experiment (due to the high correlation value), are now ready for use in the form of a matrix or data-table (look-up table).

\section{CONCLUSION}

Rapid development in the field of electronics has enabled major advances in all branches of technics and drive technology is no exception. The investment cost of purchasing frequency controlled drives has greatly reduced in recent years. Thus, in the field of hydraulic drive technology there are new trends in the constructions of modern power units. Affordable electric drives controlled by frequency converters have opened new fields of applications, in particular applications with a constant displacement pumps. In recent times they are also being used in combination with variable displacement pumps. In the second case, we have the ability to simultaneously adjust two components: the speed of the electric motor and the 
swash plate angle of the pump (its displacement). Such a power train allows us to set both components, regardless of their current operating points, to their maximum efficiency fields maximum efficiency drive concept. The pre-condition is of course sufficient and precise knowledge of the efficiency fields of individual components and the entire power train.

This paper has initially presented an approach for determining the efficiency fields on the basis of simulation, which demands fairly accurate knowledge of individual components' functioning necessary for the design of the models, and then the experimental measurements. Comparison with the experimentally obtained results for efficiency fields showed a very high degree of correlation. Thus, the pre-prepared models of components can be used for similar power trains: other drive concepts where only one component, either pump or motor, is adjustable.

Determination of the efficiency field, both on the basis of simulation or experiment, is quite extensive but routine work, which can be automated in both cases - the series of operating parameters and settings of components can be automatically changed and obtained values can be stored within an appropriate database format. Based on the obtained results the frequencies of the observed operating points can be increased in the areas in which the efficiency fields vary considerably, to refine the network of results, either by the simulation or the experiment.

\section{ACKNOWLEDGEMENT}

Operation part has been financed by the European Union, European Social Fund. Operation is implemented in the framework of the Operational Programme for Human Resources Development for the Period 2007 axis 1: Promoting entrepreneurship and adaptability, Main type of activity 1.1.: Experts and researchers for competitive enterprises.

\section{REFERENCES}

[1] Lovrec, D.; Ulaga, S. (2007). Pressure control in hydraulic systems with variable or constant pumps?, Experimental Techniques, Vol. 31, No. 2, 33-41, doi:10.1111/j.1747-1567.2007.00146.x

[2] Xu, M.; Jin, B.; Chen, G.; Ni, J. (2013). Speed-control of energy regulation based variable-speed electrohydraulic drive, Strojniski vestnik - Journal of Mechanical Engineering, Vol. 59, No. 7-8, 433-442, doi:10.5545/sv-jme.2012.911

[3] Ferreira, F. J. T. E.; Fong, J. A. C.; De Almeida, A. T. (2011). Ecoanalysis of variable-speed drives for flow regulation in pumping systems, IEEE Transactions on Industrial Electronics, Vol. 58, No. 6, 2117-2125, doi:10.1109/TIE.2010.2057232

[4] Lovrec, D.; Kastrevc, M.; Ulaga, S. (2009). Electro-hydraulic load sensing with a speedcontrolled hydraulic supply system on forming-machines, The International Journal of Advanced Manufacturing Technology, Vol. 41, No. 11-12, 1066-1075, doi:10.1007/s00170-008-1553-y

[5] Tašner, T.; Lovrec, D. (2013). Energy saving eta drive concept for electrohydraulic systems, Prooceedings of the Internationan Conference Fluid Power 2013, Maribor, 27-42

[6] Diaz, A.; Saltares, R.; Rodriguez, C.; Nunez, R. F.; Ortiz-Rivera, E. I.; Gonzalez-Llorente, J. (2009). Induction motor equivalent circuit for dynamic simulation, IEEE International Electric Machines and Drives Conference (IEMDC '09), 858-863, doi:10.1109/IEMDC.2009.5075304

[7] Delaleau, E.; Louis, J.-P.; Ortega, R. (2001). Modeling and control of induction motors, International Journal of Applied Mathematics and Computer Science, Vol. 11, No. 1, 105-129

[8] Tašner, T.; Tič, V.; Lovrec, D. (2013). Advanced control concepts suitable for energy efficient hydraulic systems, SIMULTECH 2013, $3^{\text {rd }}$ International Conference on Simulation and Modeling Methodologies, Technologies and Applications, Reykjavík, 3-11

[9] Holmes, D. G., Lipo, A. T. (2003). Pulse width modulation for power converters - Principles and practice, $1^{\text {st }}$ ed., John Wiley \& Sons, Inc., Hoboken 
[10] Shen, Z. J.; Xiong, Y.; Cheng, X.; Fu, Y.; Kumar, P. (2006). Power MOSFET switching loss analysis: a new insight, Conference Record of the 2006 IEEE Industry Applications Conference, $41^{\text {st }}$ IAS Annual Meeting, Vol. 3, 1438-1442, doi:10.1109/IAS.2006.256719

[11] Stekl, P. (2007). 3-phase AC Induction Vector Control Drive with Single Shunt Current Sensing, Designer Reference Manual, Freescale Semiconductor, Roznov

[12] Wilson, E. W. (1948). Performance criteria for positive displacement pumps and fluid motors, ASME Semi-Annual Meeting, paper No. 48-SA-14

[13] Rydberg, K.-E. (2009). Efficiencies for variable hydraulic pumps and motors - Mathematical models and operation conditions, from http://www.iei.liu.se/flumes/tmms10/filarkiv/kursmaterial/ 1.138187/Efficienciesforvariablemachines_tmms10.pdf, accessed on 26-03-2013

[14] Jeong, H.-S.; Kim, H.-E. (2007). A novel performance model given by the physical dimensions of hydraulic axial piston motors: Experimental analysis, Journal of Mechanical Science and Technology, Vol. 21, No. 4, 630-641, doi:10.1007/BF03026968

[15] Ancic, I.; Sestan, A.; Virag, Z. (2014). Determination of actual discharge of high-pressure lowdischarge axial piston pumps, Transactions of FAMENA, Vol. 38, No. 2, 1-10

[16] Lovrec, D.; Kastrevc, M. (2011). Modelling and simulating a controlled press-brake supply system, International Journal of Simulation Modelling, Vol. 10, No. 3, 133-144, doi:10.2507/IJSIMM10(3)3.184 